\title{
The Asp298Asn missense mutation in the porcine melanocortin-4 receptor (MC4R) gene can be used to affect growth and carcass traits without an effect on meat quality
}

\author{
K. Van den Maagdenberg ${ }^{1}$, A. Stinckens ${ }^{2}$, E. Claeys ${ }^{1}$, M. Seynaeve ${ }^{1}$, A. Clinquart ${ }^{3}$, \\ M. Georges ${ }^{4}$, N. Buys ${ }^{2}$ and S. De Smet ${ }^{1+}$ \\ ${ }^{1}$ Laboratory for Animal Nutrition and Animal Product Quality, Department of Animal Production, Ghent University, Proefhoevestraat 10, 9090 Melle, Belgium; \\ ${ }^{2}$ Laboratory of Livestock Physiology, Immunology and Genetics, KU Leuven, Kasteelpark 30, 3001 Heverlee, Belgium; ${ }^{3}$ Laboratory of Food Technology, \\ Department of Food Science, University of Liège, 20 Boulevard de Colonster, 4000 Liège, Belgium; ${ }^{4}$ Unit of Animal Genomics, University of Liège, \\ 20 Boulevard de Colonster, 4000 Liège, Belgium
}

(Received 10 April 2007; Accepted 11 June 2007)

\begin{abstract}
A promising tool to improve daily gain in pigs is the missense mutation (Asp298Asn) in the melanocortin-4 receptor (MC4R) gene, especially in the Belgian pig industry where the slow-growing Piétrain breed is very frequently used as the sire breed. The MC4R is expressed in the appetite-regulating region of the brain where it regulates feed intake and energy balance. The mutation has been associated with differences in fatness, daily gain and feed intake. However, less information on the correlated effects on meat quality is available. In order to evaluate the influence of the MC4R mutation on carcass and meat quality parameters, a total of 1155 pigs of a four-way cross were slaughtered at an average live weight of $109 \mathrm{~kg}$, and data about daily live-weight gain, carcass and meat quality were collected. Allelic frequencies were 0.69 for the $G$-allele (298Asp variant or well-conserved variant) and 0.31 for the A-allele (298Asn variant or the mutated variant). Barrows and gilts were almost equally distributed in this population with, respectively, $49.9 \%$ and $50.1 \%$. Moreover, independent of this mutation, the relationship between average daily gain (ADG) and carcass on the one hand and meat quality traits on the other hand was evaluated in this population. A significant positive influence of the MC4R mutation on ADG $(P<0.001)$ was found, accompanied by a higher fat thickness $(\mathrm{P}<0.05)$ and a lower carcass lean meat content $(\mathrm{P}<0.01)$, whereas muscle thickness and carcass conformation traits were not affected. The effects on meat quality traits were not significant, except for a lower shear force $(\mathbb{P}=0.054)$ and a higher intramuscular fat content $(\mathrm{P}=0.052)$ in $A A$ animals. In the longissimus, $p H$ and pork quality meter (PQM) values were not influenced, and effects on drip loss and colour were not apparent. Residual correlation coefficients between $A D G$ and carcass lean meat content on the one hand and meat quality traits on the other hand were generally very low $(\mid r />0.1)$. Higher $A D G$, higher carcass fat thickness and lower carcass lean meat content were correlated with slightly lower shear force values $(\mid \mathrm{r} / \sim 0.1, \mathrm{P}<0.05)$. In conclusion, in the studied population, the Asp298Asn mutation in the MC4R gene was associated with improved daily gain, higher carcass fatness and almost no effect on meat quality traits.
\end{abstract}

Keywords: average daily gain, carcass quality, melanocortin-4 receptor, meat quality, pigs

\section{Introduction}

Carcass composition and growth traits are of great economic importance in commercial pig production. Hence, these traits receive considerable interest in pig breeding programmes. With the advent of molecular genetic tools,

\footnotetext{
${ }^{\dagger}$ E-mail: Stefaan.DeSmet@UGent.be. Present address: Laboratory for Animal Nutrition and Animal Product Quality, Department of Animal Production, Ghent University, Proefhoevestraat 10, 9090 Melle, Belgium.
}

selection may be further improved based on mutations in candidate genes or quantitative trait loci (QTL), e.g. the IGF-2 mutation in pigs affecting the percentage lean meat (Van Laere et al., 2003). However, improvement of performance traits may be associated with undesirable effects on meat quality, as has been clearly evidenced in the case of the RYR1 and the RN mutation (De Smet et al., 1995; Sellier, 1998; Hamilton et al., 2000). Therefore, the search for new gene-based selection tools aiming at improving 
performance traits has to be accompanied by an evaluation of the correlated effects on pork quality.

In the pig, an association between a MC4R Asp298Asn missense mutation and fatness, increased daily gain and increased feed intake was first demonstrated by Kim et al. (2000). This seems a promising tool to improve daily gain, especially in the Belgian pig industry where the slowgrowing Piétrain breed is very frequently used as the sire breed. The MC4R receptor is expressed in the appetiteregulating region of the brain where it regulates feed intake and energy balance. The Asp298Asn mutation occurs within a highly conserved region where Asp298 is required for normal MC4R signalling. The Asn298 variant decreases $M C 4 R$ signalling without differences in the ligand binding (Kim et al., 2004). The effect of the Asp298Asn substitution in MC4R is not reported to be uniform, but rather a blend of effects on average daily gain (ADG), feed intake, lean growth, carcass fat and carcass length (Kim et al., 2000; Park et al., 2002; Hernández-Sánchez et al., 2003; Stachowiak et al., 2005; Bruun et al., 2006). The aim of the current study was to evaluate the effect of the $M C 4 R$ missense mutation on carcass and meat quality traits in a commercial four-way cross population. Moreover, independent of this mutation, the relationships between ADG and carcass and meat quality traits were evaluated in this population. It is well known that some meat quality traits may be negatively affected in very lean pigs, although the effects of intense selection for ADG and leanness on meat quality traits depend on the specific meat quality trait and are not unequivocal in literature (Sellier, 1998).

\section{Material and methods}

\section{Animals and experimental set-up}

Animals were the offspring from a commercial four-way cross. Hybrid sows originated from a Landrace $\times$ Large White intercross mainly selected for number of pigs born alive, number of pigs weaned and longevity. Sires originated from a line based on Large White and Piétrain, mainly selected for ADG and carcass lean meat content. The distribution among the five sires and gender is given in Table 1. The animals were all born on the same farm and were transferred after 2 months to the finishing farm. The pigs were fed a commercial diet ad libitum and were slaughtered at a target live weight of $110 \mathrm{~kg}$. A total of 1155 animals were slaughtered in the abattoir of Ghent University on 25 different slaughter days (approximately 45 pigs per slaughter day). Pigs were bled following manual electrical stunning (240 V). Before slaughter, feed was withdrawn overnight and the pigs were allowed to rest after transportation for a minimum of $1 \mathrm{~h}$. Based on the time of slaughter, the time of feed withdrawal and the arrival time of the pigs at the slaughterhouse, starvation time and lairage time were calculated in hours and decimal minutes. Starvation time ranged between 4.3 and $22.0 \mathrm{~h}$ (average 16.6) and the lairage time varied between 0.4 and $15.8 \mathrm{~h}$ (average 4.1).
Table 1 Distribution of the pigs $(\mathrm{n}=1155)$ according to the genotype for the MC4R genotype, gender and sire

\begin{tabular}{llrrrrrr}
\hline \hline \multirow{2}{*}{ Gender } & & \multicolumn{6}{c}{ Sire } \\
\cline { 3 - 8 } & MC4R & Sire 1 & Sire 2 & Sire 3 & Sire 4 & Sire 5 & Total \\
\hline Barrows & AA & 34 & 15 & & & & 49 \\
& GA & 53 & 55 & 31 & 60 & 59 & 258 \\
& GG & 36 & 43 & 45 & 44 & 101 & 269 \\
& Total & 123 & 113 & 76 & 104 & 160 & 576 \\
& & & & & & & \\
Gilts & AA & 24 & 22 & & & & 46 \\
& GA & 50 & 39 & 40 & 66 & 71 & 266 \\
& GG & 25 & 33 & 48 & 67 & 94 & 267 \\
& Total & 99 & 94 & 88 & 133 & 165 & 579 \\
& & & & & & & \\
Total & & 222 & 207 & 164 & 237 & 325 & 1155 \\
\hline \hline
\end{tabular}

Abbreviation is: $M C 4 R=$ melanocortin-4 receptor genotype.

\section{Animal and carcass quality data}

Live weight $(\mathrm{kg})$ and warm carcass weight $(\mathrm{kg})$ were recorded before stunning and at the end of the slaughter line, respectively. Dressing yield (\%) was calculated based on cold carcass weight ( $98 \%$ of the warm carcass weight). ADG ( $g /$ day) was calculated as the live weight divided by the number of days from birth to slaughter. Average daily carcass lean meat gain (ADLMG, g/day) was calculated as the cold carcass weight multiplied by the percentage lean meat estimated with the CGM device (Capteur Gras/Maigre, Sydel, Lorient, France), divided by the number of days from birth to slaughter.

Instrumental carcass grading was performed using the CGM device (Sydel, France) and the SKGII apparatus (Eurocontroll Belgium, Vilvoorde, Belgium). With the CGM apparatus, fat and muscle thickness $(\mathrm{mm})$ were measured at the level of 3rd to 4th last rib using light reflection and the carcass lean meat percentage (LMP) was estimated by using the regression formulae as approved for use in Belgian abattoirs. The SKGII device combines four physical measurements (fat thickness $(\mathrm{mm})$, ham width $(\mathrm{mm})$, loin width (mm) and ham angle (deg.)) to estimate the type index as a measure for conformation (Branscheid and Sack, 1988). The type index has to be interpreted as lower values indicating more muscular conformation. In addition, fat depth $(\mathrm{mm})$ was manually measured on the cutting edge at rib 1, rib 7 and lumbar vertebra 3. The number of ribs and vertebra and carcass length $(\mathrm{cm})$, assessed as the distance from the posterior edge of the symphysis pubis to the cranial edge of the first rib, were recorded as well.

\section{Meat quality measurements}

The $\mathrm{pH}$ was measured $40 \mathrm{~min}$ and $24 \mathrm{~h}$ after slaughtering in the longissimus at the level of the 3rd-4th last rib (pH1L and $\mathrm{pH} 2 \mathrm{~L}$ ) and in the ham (semimembranosus) (pH1H and pH2H) using a Knick Portamess 654 pH meter (Knick, Berlin, Germany) equipped with an Mettler Toledo 
LoT406-M6-DXK-S7/25 electrode (Urdorf, Switzerland). Temperature of the carcass was also measured at $40 \mathrm{~min}$ after slaughtering in the longissimus (Temp $1 \mathrm{~L})\left({ }^{\circ} \mathrm{C}\right)$. Conductivity $(\mu \mathrm{S})$ was measured at $24 \mathrm{~h}$ post mortem in the longissimus (PQM2L) and semimembranosus ( $\mathrm{PQM} 2 \mathrm{H}$ ) using a pork quality meter (PQM; Tecpro $\mathrm{GmbH}$, Aichach, Germany). The average of the measurements of $\mathrm{pH}, \mathrm{PQM}$ and temperature on both carcass sides for each animal was used for further calculations.

One day post mortem $(24 \mathrm{~h})$, a piece of the longissimus from the left carcass side at the level of the last thoracic vertebra and first two lumbar vertebra was removed (approximate thickness $7 \mathrm{~cm}$ ), deboned and sliced. One slice was used for colour measurements using the sixpoint Japanese pork colour scale (FHK Co., Tokyo, Japan) $(1=$ PSE, $6=$ DFD) and by determining the CIELAB colour co-ordinates $\left(L^{*}, a^{*}\right.$ and $\left.b^{*}\right)$ in quadruplicate with a HunterLab MiniScan device after $30 \mathrm{~min}$ blooming time (D65 light source, $10^{\circ}$ standard observer, $45^{\circ} / 0^{\circ}$ geometry, 1-in light surface, white standard; Hunter, Reston, USA). Drip loss was assessed in duplicate as the uptake of fluid (mg) using the filter paper method of Kauffman et al. (1996). Thaw loss (\%) was determined as the difference between the initial weight of a sample before frozen storage at $-18^{\circ} \mathrm{C}$ in a vacuum bag and the weight after overnight thawing at $4^{\circ} \mathrm{C}$, divided by the initial weight. Cooking loss (\%) was determined as the difference of the sample weight before and after cooking the sample in a open plastic bag in water at $70^{\circ} \mathrm{C}$ for 40 min followed by cooling in cold running tap water for $15 \mathrm{~min}$, divided by the initial weight. Tenderness was evaluated by shear force determination on the cooked samples. Shear force $(\mathrm{N})$ and total work (area under the curve, $\mathrm{N} \cdot \mathrm{mm}$ ) were measured on cylindrical cores $(\emptyset 1.27 \mathrm{~cm})$ taken parallel and sheared perpendicular to the longitudinal orientation of the muscle fibres, using a Lloyd TA 500 Texture Analyser (Lloyd Instruments, Fareham, Hampshire, UK) equipped with a triangular Warner-Bratzler shear device. A mean of eight measurements were used for further analysis. Total work was divided into myofribrillar work $(\mathrm{N} \cdot \mathrm{mm})$ and collagen work $(\mathrm{N} \cdot \mathrm{mm})$ as an estimate of the respective contributions of myofibrillar and collagen component to toughness. Myofibrillar work is the area under the first peak and the area difference between total work and myofibrillar work is designated as collagen work (Claeys et al., 2000). Finally, intramuscular fat (IMF) content was measured on thawed longissimus homogenates with near infrared spectroscopy, calibrated with IMF values determined by the Soxhlet method on 184 samples (mean $1.42 \%$, s.d. $0.62 \%$, min. $0.37 \%$, max. $4.43 \%$ ). The calibration and measurements were performed as described by Meulemans et al. (2002) for technological and organoleptical properties of pork. The best predictive model was selected based on the lowest standard error of cross-validation $\left(\mathrm{SE}_{\mathrm{CV}}\right)$ and the highest determination coefficient of cross-validation $\left(R^{2} \mathrm{cv}\right)$, which were 0.27 and 0.80 , respectively. This model was then used to predict the ether content of all other samples.

\section{Statistics}

The effect of the $M C 4 R$ mutation was analysed with a univariate GLM with $M C 4 R$ genotype $(M C 4 R)$, gender $(\mathrm{G})$ and sire $(S)$ as fixed factors and slaughter day as random factor for the meat quality traits. The effect of starvation and lairage time were evaluated in preliminary analyses, but these factors did not appear to yield additional information above slaughter day, and therefore were not included in the model. No effects of the two-way interactions were found in the preliminary analyses, and therefore these terms were also excluded from the final model. When the MC4R mutation had a significant effect, means were compared with the Tukey's comparison of mean test. The Pearson's correlation coefficients between the residuals of all univariate models were used to examine the relationships between the carcass and meat quality traits after correction for the fixed effects. All data were analysed using SPSS 12.0 for windows (Statistical Packages for the Social Sciences, 2003).

\section{Results}

\section{Growth and carcass parameters}

Pigs were slaughtered at an average ( \pm s.d.) live weight of $109 \pm 8 \mathrm{~kg}$. The allelic frequencies of the MC4R mutation were 0.69 for the $298 \mathrm{Asp}$ variant or G-allele and 0.31 for the 298Asn variant or A-allele. Live weight was not different between the MC4R genotypes (Table 2). However, the days to reach this slaughter weight and thus also ADG differed significantly according to the MC4R mutation. Based on the least-square means, animals with the $A A$ genotype grew approximately $25 \mathrm{~g} /$ day faster than their GG genotype counter mates. Animals heterozygous for the $M C 4 R$ mutation were intermediate and different from the homozygous genotypes $(P<0.05)$.

The increased ADG of the MC4R mutation was accompanied by a lower LMP and a higher fat thickness, measured with the CGM device as well as measured manually $(P<0.05)$. The CGM muscle thickness was not influenced. The traits related to conformation (ham width, ham angle, type index and carcass length) were not affected by the $M C 4 R$ mutation. The number of ribs and vertebra were also not different. The fat thickness and LMP values of the heterozygous animals were intermediate and were different from the values of the $\mathrm{GG}$ animals $(P<0.05)$. As a resultant from the opposite effects of the MC4R mutation on $A D G$ and LMP, differences between MC4R genotypes for ADLMG were rather small $(P<0.1)$, but AA animals still displayed higher values than GG animals with the heterozygous animals being intermediate $(P<0.05)$.

Gilts grew slower than barrows $(P<0.001)$. Gender also influenced LMP, fat thickness as well as muscle thickness $(P<0.001)$, with the gilts having a leaner carcass compared with the barrows. Moreover, carcass length was increased in gilts $(P<0.001)$ and the SKGII measures were also different for barrows and gilts resulting in a lower and thus better type index for gilts $(P<0.001)$. ADLMG was 
Van den Maagdenberg, Stinckens, Claeys, Seynaeve, Clinquart, Georges, Buys and De Smet

Table 2 Least square means \pm s.e. for growth and carcass quality traits by the MC4R genotype

\begin{tabular}{|c|c|c|c|c|c|c|c|c|c|}
\hline & \multicolumn{6}{|c|}{$M C 4 R$ genotype } & & & \\
\hline & \multicolumn{2}{|c|}{$\begin{array}{c}\mathrm{AA} \\
(n=87-95)\end{array}$} & \multicolumn{2}{|c|}{$\begin{array}{c}\mathrm{GA} \\
(n=507-524)\end{array}$} & \multicolumn{2}{|c|}{$\begin{array}{c}\mathrm{GG} \\
(n=524-536)\end{array}$} & \multicolumn{3}{|c|}{ GLM significance } \\
\hline & Mean & s.e. & Mean & s.e. & Mean & s.e. & $M C 4 R$ & G & $S$ \\
\hline Age (days) & $209.5^{a}$ & 2.0 & $214.5^{b}$ & 0.8 & $217.1^{c}$ & 0.8 & $* * *$ & $* * *$ & $* * *$ \\
\hline Live weight $(\mathrm{kg})$ & 110.4 & 0.9 & 110.0 & 0.4 & 109.3 & 0.4 & & & $* * *$ \\
\hline ADG $(g / d a y)^{+}$ & $531^{a}$ & 5 & $516^{\mathrm{b}}$ & 2 & $507^{c}$ & 2 & $* * *$ & $* * *$ & $* * *$ \\
\hline ADLMG $(g / \text { day })^{\ddagger}$ & $242^{\mathrm{a}}$ & 3 & $240^{\mathrm{b}}$ & 1 & $237^{c}$ & 1 & 0.058 & $* * *$ & $* * *$ \\
\hline Warm carcass weight $(\mathrm{kg})$ & 89.0 & 0.7 & 89.1 & 0.3 & 88.3 & 0.3 & & & $* * *$ \\
\hline Dressing yield (\%) & $79.05^{a}$ & 0.22 & $79.47^{b}$ & 0.09 & $79.24^{b}$ & 0.09 & 0.062 & & $* * *$ \\
\hline Carcass length (cm) & 82.68 & 0.31 & 82.71 & 0.12 & 82.51 & 0.13 & & $* * *$ & $* * *$ \\
\hline Number of ribs & 15.03 & 0.06 & 15.07 & 0.02 & 15.08 & 0.02 & & & $* * *$ \\
\hline Number of vertebra & 21.11 & 0.04 & 21.14 & 0.01 & 21.14 & 0.01 & & & $* * *$ \\
\hline Fat thickness $(\mathrm{mm})^{\S}$ & $14.58^{\mathrm{a}}$ & 0.33 & $13.91^{\mathrm{a}}$ & 0.13 & $13.46^{\mathrm{b}}$ & 0.13 & $* *$ & $* * *$ & $* * *$ \\
\hline Muscle thickness $(\mathrm{mm})^{\S}$ & 58.61 & 0.65 & 58.29 & 0.25 & 58.42 & 0.26 & & $* * *$ & *** \\
\hline$\%$ Lean meat ${ }^{\S}$ & $57.88^{\mathrm{a}}$ & 0.38 & $58.52^{a}$ & 0.15 & $59.02^{b}$ & 0.15 & ** & $* * *$ & * \\
\hline $\operatorname{Rib} 1(\mathrm{~mm})$ & 34.17 & 0.58 & 32.91 & 0.23 & 32.96 & 0.24 & & $* * *$ & *** \\
\hline $\operatorname{Rib} 7$ (mm) & $26.08^{a}$ & 0.53 & $25.10^{\mathrm{a}}$ & 0.21 & $24.15^{\mathrm{b}}$ & 0.21 & $* * *$ & $* * *$ & $* * *$ \\
\hline Vertebra $3(\mathrm{~mm})$ & $26.17^{\mathrm{a}}$ & 0.50 & $25.12^{\mathrm{b}}$ & 0.20 & $24.68^{b}$ & 0.20 & * & *** & \\
\hline Loin width $(\mathrm{mm})^{\|}$ & 134.3 & 0.7 & 133.4 & 0.3 & 132.6 & 0.3 & * & $* * *$ & $* * *$ \\
\hline Ham width (mm) $\|$ & 201.3 & 1.0 & 201.3 & 0.4 & 200.9 & 0.4 & & * & $* * *$ \\
\hline Ham angle (deg.)" & 41.69 & 0.51 & 41.75 & 0.20 & 41.75 & 0.21 & & * & $* * *$ \\
\hline Type index & 1.96 & 0.03 & 1.96 & 0.01 & 1.95 & 0.01 & & $* * *$ & ** \\
\hline
\end{tabular}

Abbreviations are: s.e. = standard error, $M C 4 R=$ melanocortin-4 receptor genotype, GLM = general linear model, $\mathrm{G}=$ gender and $\mathrm{S}=$ sire effect, $A D G=$ average daily gain, $A D L M G=$ average daily carcass lean meat growth.

$a, b, c$ Means for the effect of line lacking a common superscript letter differ $(P<0.05)$.

${ }^{+} A D G$ was calculated as the live weight divided by the number of days from birth to slaughter.

${ }^{\ddagger}$ ADLMG was calculated as the carcass weight multiplied by the percentage lean meat estimated with the CGM (Capteur Gras/Maigre) device, divided by the number of days from birth to slaughter.

Fat and meat thickness were recorded at the level of the 3rd to 4 th last rib using light reflection and \% lean meat was estimated by using the official regression formulae.

"Loin width, ham width, fat thickness and ham angle are SKGIl measures that are used in a regression formula for the estimation of the type index.

${ }^{* * *} P<0.001,{ }^{* *} P<0.01,{ }^{*} P<0.05$ and empty cells $=P>0.1$.

slightly higher for gilts than for barrows $(P<0.001)$ (data not shown).

There was also an effect of sire on ADG and ADLMG $(P<0.001)$, and on LMP and carcass conformation traits $(P<0.05)$, except for muscle thickness and ham angle. When only the two sires having progeny with the three genotypes were considered, the differences in ADG and ADLMG were also significant $(P<0.001$, data not shown).

\section{Meat quality traits}

The least-square means for meat quality traits by $M C 4 R$ mutation are shown in Table 3. No differences were found for the MC4R genotypes for all meat quality traits except for shear force parameters and IMF content. The $\mathrm{pH}$ and $\mathrm{PQM}$ at $40 \mathrm{~min}$ and $24 \mathrm{~h}$ post mortem were similar for the three genotypes, except a small difference $(P<0.1)$ for $\mathrm{PH} 1 \mathrm{~L}$ and PQM2L. The meat from animals with the GG genotype had higher shear force values compared with meat from animals with genotypes $A A$ and $G A$ $(P<0.1)$. The higher shear force values were due to a higher myofibrillar work component $(P<0.05)$, whereas the collagen work component was not affected. The shear force values for $A A$ and $G A$ animals were similar. The $G G$ animals had a lower IMF content compared with AA animals, with the heterozygous animals being intermediate $(P<0.05)$.

Slaughter day, included in the model as a random factor, was significant $(P<0.001)$ for all meat quality traits (data not shown). Also, sire had a significant effect on all meat quality traits, except for the shear force parameters. Gender had a significant influence on several meat quality traits, although the differences were small. The meat from gilts was less pale and more red, had lower thawing losses, higher shear force values compared with barrows and contained less IMF (data not shown).

\section{Relationship between lean meat gain parameters and meat quality traits}

The residual correlation coefficients between lean meat gain parameters and meat quality traits are shown in Table 4. As expected, the relationships between ADG on one hand and LMP and type index on the other hand were negative, and those between ADG, muscle thickness and ADLMG were positive. 
Table 3 Least-square means \pm s.e. for meat quality traits by the MC4R genotype

\begin{tabular}{|c|c|c|c|c|c|c|c|c|c|}
\hline & \multicolumn{6}{|c|}{ MC4R genotype } & & & \\
\hline & \multicolumn{2}{|c|}{$\begin{array}{c}\mathrm{AA} \\
(n=89-95)\end{array}$} & \multicolumn{2}{|c|}{$\begin{array}{c}\mathrm{GA} \\
(n=454-523)\end{array}$} & \multicolumn{2}{|c|}{$\begin{array}{c}\mathrm{GG} \\
(n=466-536)\end{array}$} & \multicolumn{3}{|c|}{ GLM significance ${ }^{\ddagger}$} \\
\hline & Mean & s.e. & Mean & s.e. & Mean & s.e. & MC4R & G & $S$ \\
\hline pH1 loin & 6.24 & 0.02 & 6.20 & 0.01 & 6.21 & 0.01 & 0.090 & & *** \\
\hline pH1 ham & 6.30 & 0.02 & 6.29 & 0.01 & 6.29 & 0.01 & & & * \\
\hline Temperature1 loin $\left({ }^{\circ} \mathrm{C}\right)$ & 39.36 & 0.08 & 39.37 & 0.03 & 39.32 & 0.03 & & 0.095 & $* * *$ \\
\hline pH2 loin & 5.53 & 0.01 & 5.53 & 0.00 & 5.53 & 0.00 & & & $* * *$ \\
\hline $\mathrm{pH} 2$ ham & 5.60 & 0.01 & 5.58 & 0.01 & 5.58 & 0.01 & & $* * *$ & * \\
\hline PQM2 loin $(\mu S)$ & 5.58 & 0.17 & 5.95 & 0.07 & 5.80 & 0.08 & 0.078 & & *** \\
\hline PQM2 ham $(\mu S)$ & 8.19 & 0.20 & 8.34 & 0.08 & 8.44 & 0.09 & & $* * *$ & * \\
\hline CIELAB $L^{*}$ & 53.84 & 0.33 & 53.87 & 0.13 & 53.53 & 0.14 & & $* * *$ & $* * *$ \\
\hline CIELAB $a^{*}$ & 6.62 & 0.10 & 6.62 & 0.04 & 6.61 & 0.04 & & $* * *$ & ** \\
\hline CIELAB $b^{*}$ & 15.11 & 0.08 & 15.19 & 0.03 & 15.11 & 0.03 & & & ** \\
\hline Japanese colour scale & 2.52 & 0.05 & 2.47 & 0.02 & 2.48 & 0.02 & & $* * *$ & * \\
\hline Drip (FPM) (mg) & 61.47 & 2.57 & 64.81 & 1.04 & 64.19 & 1.07 & & & $* * *$ \\
\hline Thawing losses (\%) & 13.95 & 0.29 & 13.94 & 0.12 & 14.02 & 0.12 & & ** & \\
\hline Cooking losses (\%) & 26.71 & 0.22 & 26.51 & 0.09 & 26.44 & 0.09 & & & $* * *$ \\
\hline Shear force $(\mathrm{N})$ & $34.78^{\mathrm{ab}}$ & 0.66 & $34.85^{\mathrm{a}}$ & 0.26 & $35.71^{\mathrm{b}}$ & 0.27 & 0.054 & $* * *$ & \\
\hline Work $(\mathrm{N} \cdot \mathrm{mm})$ & 294.5 & 5.1 & 296.5 & 2.0 & 301.7 & 2.1 & & $* * *$ & \\
\hline Myofibrillar work (N · mm) & $171.5^{\mathrm{ab}}$ & 4.0 & $170.8^{\mathrm{a}}$ & 1.6 & $177.1^{b}$ & 1.7 & * & $* * *$ & \\
\hline Collagen work $(\mathrm{N} \cdot \mathrm{mm})$ & 123.0 & 2.2 & 125.7 & 0.9 & 124.6 & 0.9 & & $* * *$ & \\
\hline $\mathrm{IMF}^{+}$ & $1.17^{\mathrm{a}}$ & 0.06 & $1.13^{b}$ & 0.02 & $1.06^{\mathrm{c}}$ & 0.02 & 0.052 & $* * *$ & $* * *$ \\
\hline
\end{tabular}

Abbreviations are: s.e. $=$ standard error, $M C 4 R=$ melanocortin- 4 receptor genotype, $\mathrm{GLM}=$ general linear model, $\mathrm{G}=$ gender, and $\mathrm{S}=$ sire effect, $\mathrm{IMF}=$ intramuscular fat.

a,b,c Means for the effect of line lacking a common superscript letter differ $(P<0.05)$.

${ }^{\dagger}$ IMF content measured with near-infrared spectroscopy on $55 \mathrm{AA}, 332 \mathrm{GA}$ and $358 \mathrm{GG}$ animals.

${ }^{* *} P<0.001,{ }^{* *} P<0.01,{ }^{*} P<0.05$ and empty cells $=P>0.1$.

No relationships were apparent between ADG and most meat quality traits, except a negative relationship with the shear force traits and cooking losses and a positive relationship with drip loss and IMF. The pH1H was negatively related to $L M P$ and $P Q M 2 L$ was positively related with $L M P$. Shear force traits, cooking losses and $L^{*}$ values showed a positive relationship with LMP and IMF was negatively related with LMP. Fat thickness was negatively related to the shear force traits and cooking losses, and a positive relationship between fat thickness and IMF, pH2 in loin and ham was apparent. In contrast, muscle thickness was not related to shear force parameters and IMF, but positive residual correlation coefficients were found with Temp1L, $\mathrm{pH} 2$ ham, PQM2 in loin and ham, $L^{*}$ and $b^{*}$ values and drip and negative coefficients with $\mathrm{pH} 1$ in loin and ham and cooking losses. The type index, as a measure for carcass conformation, showed a negative relationship with Temp1 $\mathrm{L}$, PQM2 in loin and ham, $L^{*}$ value and drip and a positive relationship with $\mathrm{pH} 1$ in loin and ham, $a^{*}$ value and IMF.

In contrast with ADG and LMP, ADLMG was not related to the shear force parameters and IMF but a positive relationship with $\mathrm{PQM} 2$ in loin and ham, $L^{*}$ value and drip was apparent. All these correlation coefficients were rather low and at best reached values above $0.1 \mid$. In summary, shear force traits, IMF and cooking losses appeared to be more influenced by differences in ADG and fat thickness, whereas PSE-related traits ( $\mathrm{pH} 1, \mathrm{PQM}$, drip, colour $L^{*}$ value) were more affected by muscularity traits (muscle thickness, type index).

\section{Discussion}

\section{Effect of the MC4R mutation on growth, carcass and meat quality traits}

The MC4R gene has been implicated in the regulation of feeding behaviour and body weight in humans and mice (Cone, 1999). Moreover, the MC4R gene is frequently studied as a candidate gene for the control of economically important growth and performance traits in the pig. The wild-type allele (Asp298) is often associated with less backfat thickness, slower growth rate and lower feed intake, and the mutated allele (Asn298) has been associated with fatter, higher feed-consuming and faster-growing animals (Kim et al., 2000; Houston et al., 2004). Our study confirms these earlier reports. Although feed intake was not assessed in our study, similar findings with respect to growth rate and fat thickness suggest that these effects are mediated by changes in feed intake. However, it has also been hypothesised that the MC4R mutation could change the allocation of nutrients from protein deposition towards a higher fat deposition (Houston et al., 2004). This 
Van den Maagdenberg, Stinckens, Claeys, Seynaeve, Clinquart, Georges, Buys and De Smet

Table 4 Residual correlation coefficients between lean meat gain parameters and meat quality traits $^{+}$

\begin{tabular}{|c|c|c|c|c|c|c|}
\hline & ADG & LMP & ADLMG & $\begin{array}{l}\text { Fat thickness } \\
\text { (CGM) }\end{array}$ & $\begin{array}{l}\text { Muscle thickness } \\
\text { (CGM) }\end{array}$ & Type index \\
\hline \multicolumn{7}{|l|}{ Lean meat gain parameters } \\
\hline ADG (g/day) & & -0.273 & 0.777 & 0.353 & 0.117 & -0.106 \\
\hline $\operatorname{LMP}(\%)$ & -0.273 & & 0.340 & -0.921 & 0.431 & -0.415 \\
\hline ADLMG (g/day) & 0.777 & 0.340 & & -0.197 & 0.415 & -0.379 \\
\hline Fat thickness (CGM, mm) & 0.353 & -0.921 & -0.197 & & -0.046 & 0.317 \\
\hline Muscle thickness (CGM, mm) & 0.117 & 0.431 & 0.415 & -0.046 & & -0.331 \\
\hline Type index & -0.106 & -0.415 & -0.379 & 0.317 & -0.331 & \\
\hline Carcass length $(\mathrm{cm})$ & 0.371 & -0.066 & 0.318 & 0.098 & 0.058 & 0.027 \\
\hline \multicolumn{7}{|c|}{ Meat quality traits measured on the carcass post mortem } \\
\hline pH1 loin & -0.002 & -0.048 & -0.028 & -0.001 & -0.127 & 0.060 \\
\hline pH1 ham & 0.021 & -0.105 & -0.043 & 0.090 & -0.060 & 0.127 \\
\hline Temp1 loin $\left({ }^{\circ} \mathrm{C}\right)$ & 0.009 & 0.022 & 0.035 & 0.054 & 0.183 & -0.120 \\
\hline $\mathrm{pH} 2$ loin & 0.040 & -0.053 & 0.043 & 0.081 & 0.052 & 0.003 \\
\hline $\mathrm{pH} 2$ ham & 0.024 & -0.046 & 0.028 & 0.085 & 0.079 & -0.054 \\
\hline PQM2 loin $(\mu s)$ & 0.035 & 0.094 & 0.096 & -0.003 & 0.236 & -0.133 \\
\hline PQM2 ham ( $\mu$ s) & 0.037 & 0.041 & 0.065 & -0.014 & 0.073 & -0.169 \\
\hline \multicolumn{7}{|c|}{ Meat quality traits measured on a loin slice } \\
\hline CIELAB $L^{*}$ & 0.019 & 0.088 & 0.062 & -0.063 & 0.078 & -0.070 \\
\hline CIELAB $a^{*}$ & 0.008 & 0.003 & 0.002 & 0.000 & 0.009 & 0.061 \\
\hline CIELAB $b^{*}$ & 0.034 & 0.046 & 0.054 & -0.008 & 0.099 & -0.041 \\
\hline Drip (FPM) (mg) & 0.072 & 0.019 & 0.085 & 0.061 & 0.189 & -0.121 \\
\hline Thawing losses (\%) & -0.032 & 0.045 & -0.017 & -0.040 & 0.023 & -0.033 \\
\hline Cooking losses (\%) & -0.071 & 0.127 & -0.024 & -0.174 & -0.079 & -0.035 \\
\hline Shear force $(N)$ & -0.135 & 0.091 & -0.057 & -0.124 & -0.054 & -0.026 \\
\hline Total work $(\mathrm{N} \cdot \mathrm{mm})$ & -0.125 & 0.091 & -0.045 & -0.106 & -0.011 & -0.038 \\
\hline Myofribrillar work $(\mathrm{N} \cdot \mathrm{mm})$ & -0.115 & 0.081 & -0.044 & -0.106 & -0.036 & -0.031 \\
\hline Collagen work $(\mathrm{N} \cdot \mathrm{mm})$ & -0.082 & 0.064 & -0.025 & -0.053 & 0.041 & -0.032 \\
\hline IMF & 0.106 & -0.270 & -0.069 & 0.275 & -0.058 & 0.179 \\
\hline
\end{tabular}

Abbreviations are: $A D G=$ average daily gain, $L M P=$ lean meat percentage measured by CGM device, ADLMG = average daily carcass lean meat gain, CGM, CGM = Capteur Gras/Maigre device, IMF = intramuscular fat content measured with near infrared spectroscopy.

${ }^{\dagger}$ Significant correlations are shown in bold text $(P<0.05)$.

hypothesis is supported by our results. The MC4R mutation increased backfat thickness and IMF content and the higher LMP in the wild-type animals was clearly due to a lower backfat thickness, because muscle thickness was not affected. However, the effect of the MC4R gene seems to be line or breed specific. This is shown in the overview of literature data on MC4R given in Table 5. Inconsistent or even opposing effects of the $M C 4 R$ mutation on ADG and backfat thickness have been reported between or within some studies depending on the breed or line (Kim et al., 2000, in a breed based on Meishan; Park et al., 2002, in a Wild Boar $\times$ Large White intercross; Chen et al., 2005, in several breeds; Stachowiak et al., 2005, in Polish genotypes; see also Table 5). However, the majority of the data points to an increasing effect of the MC4R mutation on $A D G$, fat deposition and feed intake. This strengthens the hypothesis of Kim et al. (2000) that the observed mutation is a causal mutation. The physiological explanation of the causal effect would be a disturbed appetite control due to an alteration in the binding efficiency of a ligand to $M C 4 R$
(Kim et al., 2004). Increased feed intake is then leading to an increased ADG and fat deposition. Since growth and fat deposition are complex polygenic traits, breed- or linespecific allelic interactions that are responsible for variation in these polygenic traits might then explain the conflicting results in literature (Kim et al., 2000). Moreover, it is not excluded that the different or no effects in the given studies are due to the reduced number of animals that could limit the ability to detect small-sized effects.

Based on the allelic frequencies, the MC4R mutation has apparently been subject to negative selection in the population on the current study, because the more favourable genotype for ADG had the lowest allelic frequency. Probably, selection has been more oriented to carcass leanness in this population. Similar allelic frequencies for MC4R have been reported in several other studies; however, also, largely different allelic frequencies were found (Table 5). Moreover, Houston et al. (2004) showed that divergent selection for lean growth or feed conversion ratio altered the allelic frequencies after only seven generations of selection. 
Table 5 Overview of literature data concerning the effect of MC4R on carcass and meat quality traits ${ }^{\dagger}$

\begin{tabular}{|c|c|c|c|c|c|c|c|c|c|}
\hline \multirow[b]{2}{*}{ Reference } & \multirow[b]{2}{*}{ Breed } & \multirow[b]{2}{*}{$\begin{array}{c}\text { No. of } \\
\text { animals }^{\ddagger}\end{array}$} & \multicolumn{2}{|c|}{ Allelic frequencies } & \multicolumn{3}{|c|}{ Effect of $M C 4 R$} & \multirow[b]{2}{*}{ Others } & \multirow[b]{2}{*}{ Remarks } \\
\hline & & & $A$ & G & Growth $^{\S}$ & $\begin{array}{l}\text { Backfat } \\
\text { thickness }\end{array}$ & $\begin{array}{l}\text { Feed } \\
\text { intake }\end{array}$ & & \\
\hline \multirow[t]{6}{*}{ Kim et al. (2000) } & Synthetic line based on LR & 399 & 24.7 & 75.3 & $\mathrm{AA}>\mathrm{GG}^{\mathrm{a}}$ & $\mathrm{AA}>\mathrm{GG}^{\mathrm{a}}$ & $\mathrm{AA}<\mathrm{GG}$ & & \\
\hline & Synthetic line based on LW & 303 & 43.0 & 57.0 & $\mathrm{AA}>\mathrm{GG}$ & $\mathrm{AA}>\mathrm{GG}$ & $\mathrm{AA}>\mathrm{GG}$ & & \\
\hline & Synthetic line based on $\mathrm{LW} \times \mathrm{D}$ & 615 & 86.2 & 13.8 & $A A>A G^{a}$ & $A A>A G^{a}$ & $A A>A G$ & & $\rightarrow$ No GG genotype present \\
\hline & $\begin{array}{l}\text { Synthetic line based on several } \\
\text { breeds }(L, L W, D, P)\end{array}$ & 403 & 64.0 & 36.0 & $\mathrm{AA}>\mathrm{GG}$ & $\mathrm{AA}>\mathrm{GG}^{\mathrm{a}}$ & $\mathrm{AA}>\mathrm{GG}$ & & \\
\hline & Overall effect of the above lines & 1720 & 59.1 & 40.9 & $\mathrm{AA}>\mathrm{GG}^{\mathrm{a}}$ & $\mathrm{AA}>\mathrm{GG}^{\mathrm{a}}$ & $\mathrm{AA}>\mathrm{GG}^{\mathrm{a}}$ & & \\
\hline & $\begin{array}{l}\text { Synthetic line based on } \\
M \times L W\end{array}$ & 124 & 56.9 & 43.1 & $A A=G G$ & $\mathrm{AA}<\mathrm{GG}$ & $A A=G G$ & & $\rightarrow$ Only gilts \\
\hline Park et al. (2002) & $W B \times L W$ & 190 & 52 & 48 & $A A=G G$ & $\mathrm{AA}<\mathrm{GG}$ & No data & & $\rightarrow$ Based on QTL analysis \\
\hline \multirow{5}{*}{$\begin{array}{l}\text { Hernández-Sánchez } \\
\text { et al. (2003) }\end{array}$} & Synthetic line based on LR & 434 & 23.7 & 76.3 & $\mathrm{AA}>\mathrm{GG}^{\mathrm{a}}$ & $\mathrm{AA}>\mathrm{GG}^{\mathrm{a}}$ & $\mathrm{AA}<\mathrm{GG}$ & & \\
\hline & Synthetic line based on LW & 241 & 47.1 & 52.9 & $\mathrm{AA}=\mathrm{GG}$ & $\mathrm{AA}>\mathrm{GG}^{\mathrm{a}}$ & $A A>G G$ & & $\rightarrow$ Same but larger population as in Kim \\
\hline & Synthetic line based on $L W \times D$ & 658 & 80.8 & 19.2 & $\mathrm{AA}>\mathrm{GG}^{\mathrm{a}}$ & $\mathrm{AA}>\mathrm{GG}^{\mathrm{a}}$ & $\mathrm{AA}=\mathrm{GG}$ & & et al. $(2000)^{\bullet}$ \\
\hline & $\begin{array}{l}\text { Synthetic line based on several } \\
\text { breeds (L, LW } D, P)\end{array}$ & 435 & 63.9 & 36.1 & $\mathrm{AA}>\mathrm{GG}^{\mathrm{a}}$ & $\mathrm{AA}>\mathrm{GG}^{\mathrm{a}}$ & $\mathrm{AA}=\mathrm{GG}$ & & \\
\hline & Overall effect of the above lines & 1768 & 58.0 & 42.0 & $\mathrm{AA}>\mathrm{GG}^{\mathrm{a}}$ & $\mathrm{AA}>\mathrm{GG}^{\mathrm{a}}$ & $A A>G G$ & & \\
\hline \multirow[t]{6}{*}{ Houston et al. (2004) } & $\begin{array}{l}\text { LW selected for lean food } \\
\text { conversion HIGH }\end{array}$ & 30 & 52 & 48 & & & & & $\begin{array}{l}\rightarrow \text { Divergent selection for seven } \\
\text { generations (high/low) } \\
\rightarrow \text { General results are given for growth, } \\
\text { backfat thickness and feed intake }\end{array}$ \\
\hline & $\begin{array}{l}\text { LW selected for lean food } \\
\text { conversion LOW }\end{array}$ & 30 & 100 & 0 & & & & & \\
\hline & $\begin{array}{l}\text { LW selected for growth with } \\
\text { ad libitum feeding HIGH }\end{array}$ & 28 & 96 & 4 & $\mathrm{AA}>\mathrm{GG}^{\mathrm{a}}$ & $\mathrm{AA}>\mathrm{GG}^{\mathrm{a}}$ & $\mathrm{AA}>\mathrm{GG}^{\mathrm{a}}$ & & \\
\hline & $\begin{array}{l}\text { LW selected for growth with } \\
\text { ad libitum feeding LOW }\end{array}$ & 30 & 78 & 22 & & & & & \\
\hline & $\begin{array}{l}\text { LW selected for growth with } \\
\text { restricted feeding }\end{array}$ & $30 / 30$ & 85 & 15 & & & & $\begin{array}{l}\text { No difference in allelic } \\
\text { frequencies }\end{array}$ & \\
\hline & $\begin{array}{l}\text { LW selected for daily feed } \\
\text { intake }\end{array}$ & $30 / 30$ & 82 & 18 & & & & $\begin{array}{l}\text { No difference in allelic } \\
\text { frequencies }\end{array}$ & \\
\hline \multirow[t]{4}{*}{ Chen et al. (2005) } & LW & 32 & 69.0 & 31.0 & No data & $A A>G G$ & No data & & \\
\hline & $\mathrm{LR}$ & 43 & 81.5 & 18.5 & No data & $\mathrm{AA}<\mathrm{GG}^{\mathrm{a}}$ & No data & & \\
\hline & $M$ & 50 & 100 & & No data & $\begin{array}{l}\text { No GG } \\
\text { genotype }\end{array}$ & No data & & \\
\hline & $\mathrm{LW} \times \mathrm{LW}+\mathrm{LR}$ & 103 & 76.5 & 23.5 & No data & $\mathrm{AA}<\mathrm{GG}$ & No data & & \\
\hline
\end{tabular}


Otto et al. (2007)

$$
\begin{aligned}
& P \times L W+L R+L E \\
& P \times L W+L R \\
& P \times L W+D+L R
\end{aligned}
$$

${ }^{+}$Abbreviations are: $M C 4 R=$ melanocortin- 4 receptor genotype, $L R=$ Landrace, $L W=$ Large White, $D=$ Duroc, $P=$ Piétrain, $M=$ Meishan, $W B=$ Wild boar, $Q T L=$ quantitative trait loci, $L M P=$ lean meat percentage, IMF = intramuscular fat, $\mathrm{H}=$ Hampshire, $\mathrm{LE}=$ Leicoma, $\mathrm{T}=$ Taihu.

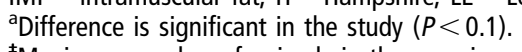

${ }^{\ddagger}$ Maximum number of animals in the experimental set-up of the study.

\$Growth can be expressed in the different reports as ADG or test daily gain or growth expressed as days to reach a specific weight.

"Although the same but more extensive population is used in this report, the numbers in Table 1 (allelic frequencies) and 3 (means) of this report give opposite results compared with the study from Kim et al. (2000). Since the values are almost similar, we assume that the definition of the genotypes in this study is wrong. We therefore used the same conclusions as in Kim et al. (2000) (e.g. $\mathrm{A}=$ allele 1 and $\mathrm{G}=$ allele 2 in Tables 1 and 3 of this report). 
To the best of our knowledge, the current study is the first one that looked simultaneously at the effect of the MC4R mutation on carcass traits and a complete set of meat quality traits in a large number of animals. The report of Óvilo et al. (2006) showed no effect on growth in a Spanish heavy breed, although a small effect on colour $\left(L^{*}\right.$ and $\left.a^{*}\right)$ was found but other meat quality traits, protein and moisture content, IMF, and $\mathrm{pH}$ were scarcely affected by MC4R. In the study of Otto et al. (2007), the favourable homozygous AA genotype was associated with darker meat and with less drip loss, but the effect of the MC4R mutation on carcass parameters was not discussed in this study. Overall, the effects of the MC4R mutation on meat quality traits seem to be of minor importance. The post mortem $\mathrm{pH}$ and PQM values reflecting the course of glycolysis were not influenced by the $M C 4 R$ genotype and consequently, no effects on drip loss or colour were to be expected. As was also reported by Otto et al. (2007), there was a tendency for reduced drip losses in the AA genotype. Only meat tenderness seemed to be influenced by MC4R. The slightly faster growing and fatter AA genotype resulted in more tender meat, due to a lower force needed to shear the myofibrillar component. The collagen component of the shear force was not affected, suggesting that collagen content or solubility were not influenced. The relationship between meat tenderness and growth is dependent on the growth mechanism in the muscle (Koohmaraie et al., 2002) and can be explained by muscle fibre size or the role of protein degradation during growth. Muscle fibre size or proteolytic enzymes were not assessed in the present study, hence their relative contribution to tenderness cannot be estimated. In addition, it is well known that the IMF content also can contribute to improved tenderness (Blanchard et al., 2000; Lebret et al., 2001), and it is possible that the slightly higher IMF content in the AA genotype is the solely mechanism for the slight decrease in shear force values in the present study.

\section{Relationship between lean meat gain parameters and meat quality traits}

In many literature studies, a negative relationship is apparent between carcass conformational traits and meat quality (reviewed by Sellier, 1998). Keeping meat quality at an acceptable level during selection for leanness has been a problem in the pig breeding industry. For instance, numerous studies have reported the positive effect of the halothane genotype on carcass lean content and conformation; however, this positive effect was often accompanied by a negative effect on meat quality traits (De Smet et al., 1995 and 1996; Leach et al., 1996). Also in other studies aiming at increasing lean tissue growth by selection or by feeding strategies, a decrease in meat quality was noticed (Karlsson et al., 1993; Oksbjerg et al., 2000). On the other hand, the IGF-2 mutation shows that selection for increased LMP does not have to have unfavourable effects on meat quality (Van den Maagdenberg et al., 2005 and unpublished results). Divergent selection for lean growth rate or efficiency of feed conversion can result in similar responses in carcass composition, but can have different effects on meat quality traits (Cameron et al., 1999). In contrast to ours, the increased ADG was not accompanied by changes in LMP in the studies of Karlsson et al. (1993) and Oksbjerg et al. (2000). In our study, higher ADG was associated with lower LMP, mainly due to a higher fat thickness. No relationship between ADG and PSE-related meat quality traits (colour, drip loss) was present in the studied population. However, a numerically negative and economically interesting relationship with shear force traits and cooking losses was found for ADG and fat thickness. As a consequence, the LMP showed an inverse relationship with shear force traits and cooking losses. A small effect of LMP on the $L^{*}$ value was also apparent. The correlation coefficients between shear force and cooking losses on the one hand with LMP and fat thickness on the other hand are in the opposite direction compared with the genetic correlations mentioned in Sellier (1998). This probably can be explained by the influence of the IMF content on tenderness (Blanchard et al., 2000; Lebret et al., 2001), because the IMF content is negatively related with the mechanical measurements for tenderness in this study (data not shown). Moreover, it has been shown before that increasing the rate of lean growth is associated with higher shear force values (Cameron et al., 1999). As mentioned before, the relationship between meat tenderness and muscle growth is primarily dependent on the mechanism responsible for differences in growth, i.e. hyperplasia $v$. hypertrophy and protein synthesis $v$. protein degradation (Koohmaraie et al., 2002). The significant residual correlation coefficients between LMP and fat thickness on the one hand and shear force on the other hand dropped from, respectively, 0.091 and -0.124 $(P<0.05)$ to 0.049 and $-0.062(P>0.05)$ when a correction was made for the IMF content in this study. A comparable decrease for total and myofibrillar work was apparent. However, although correction for the IMF content decreased the residual correlation coefficients between ADG and shear force traits from -0.135 to -0.102 , the relationship between these two parameters remained significant $(P<0.05)$. This shows that variation in IMF content contributed to variation in tenderness, but is not the only factor responsible for lower tenderness with increased ADG.

The responses of variation in ADG, LMP and ADLMG on PSE-related meat quality traits were small in the current study. However, the type index, as a measure of conformation, and muscle thickness were related to some extent to the early post mortem traits, e.g. pH1, PQM2, and Temp1, and colour and water-holding capacity. As was also argued by De Smet et al. (1997), selection for improved conformation, i.e. round shaped carcasses, is more detrimental for meat quality than leanness per se.

\section{Conclusion}

In conclusion, the $M C 4 R$ mutation has a positive influence on $A D G$, however, at the expense of increased fat thickness. 
No effects of the $M C 4 R$ mutation on meat quality traits are to be expected, except for a slightly higher shear force in wild-type animals. Residual correlation coefficients revealed that meat quality should be controlled in selection programmes that aim at increasing the efficiency of lean meat production. Carcass traits but not ADG seem to be related to meat quality.

\section{Acknowledgements}

This research is financially supported by the Institute for the Promotion of Innovation through Science and Technology, Brussels. The authors thank all the technicians of the lab and the slaughterhouse for their excellent assistance. Family Deprez and co-workers are gratefully appreciated for producing the piglets, and Rattlerow-Seghers and Gentec are thanked for the financial and technical support.

\section{References}

Blanchard PJ, Willis MB, Warkup C and Ellis M 2000. The influence of carcass backfat and intramuscular fat level on pork eating quality. Journal of Science of Food and Agriculture 80, 145-151.

Branscheid W and Sack E 1988. Comparison of objective grading devices among extremely different breeds. Pig News and Information 2, 129-135.

Bruun CS, Jørgensen CB, Nielsen VH, Andersson L and Fredholm M 2006. Evaluation of the porcine melanocortin 4 receptor $(M C 4 R)$ gene as a positional candidate for a fatness QTL in a cross between Landrace and Hampshire. Animal Genetics 37, 359-362.

Cameron ND, Nute GR, Brown SN, Enser M and Wood JD 1999. Meat quality of Large White pig genotypes selected for components of efficient lean growth rate. Animal Science 68, 115-127.

Chen JF, Xiong YZ, Zuo B, Zheng R, Li FE, Lei MG, Li JL, Deng CY and Jiang SW 2005. New evidences of effect of melanocortin-4 receptor and insulin-like growth factor 2 genes on fat deposition and carcass traits in different pig populations. Asian-Australian Journal of Animal Science 18, 1542-1547.

Claeys E, De Smet S, Balcaen A and Demeyer D 2000. Analyse du profil de la mesure de la force cisaillementVIlle Journées des Sciences du Muscle et Technologie de la Viande, Paris, France, 237-240.

Cone RD 1999. The central melanocortin system and energy homeostasis. Trends in Endocrinology and Metabolism 10, 211-216.

De Smet S, Pauwels H, Vervaeke I, Demeyer D, De Bie S, Eeckhout W and Casteels M 1995. Meat and carcass quality of heavy muscled Belgian slaughter pigs as influenced by halothane sensitivity and breed. Animal Science 61, 109-114.

De Smet S, Pauwels H, De Bie S, Demeyer D, Callewier J and Eeckhout W 1996. Effect of halothane genotype, breed, feed withdrawal and lairage on pork quality of Belgian slaughter pigs. Journal of Animal Science 74, 1854-1863.

De Smet S, Van de Voorde G and Demeyer DI 1997. Differential effect of carcass leanness and conformation on meat quality in Belgian slaughter pigs. Pig News and Information 18, 19N-22N.

Hamilton DN, Ellis M, Miller KD, McKeith FK and Parret DF 2000. The effect of the Halothane and Rendement Napole genes on carcass and meat quality characteristics. Journal of Animal Science 78, 2862-2867.

Hernández-Sánchez J, Visscher P, Plastow G and Haley C 2003. Candidate gene analysis for quantitative traits using the transmission disequilibrium test: the example of the melanocortin 4-receptor in pigs. Genetics 164 637-644.

Houston RD, Cameron ND and Rance KA 2004. A melanocortin-4 receptor (MC4R) polymorphism is associated with performance traits in divergently selected large white pig populations. Animal Genetics 35, 386-390.

Karlsson A, Enfält A, Essén-Gustavsson B, Lundström K, Rydhmer L and Stern S 1993. Muscle histochemical and biochemical properties in relation to meat quality during selection for increased lean tissue growth rate in pigs. Journal of Animal Science 71, 930-938.

Kauffman RG, Eikelenboom G, van der Wal PG, Merkus G and Zaar M 1986. The use of filter paper to estimate drip loss of porcine musculature. Meat Science 18, 191-200.

Kim KS, Larsen N, Short T, Plastow G and Rothschild MF 2000. A missense variant of the porcine melanocortin-4 receptor $(M C 4 R)$ gene is associated with fatness, growth, and feed intake traits. Mammalian Genome 11, 131-135.

Kim KS, Reecy JM, Hsu WH, Anderson LL and Rothschild MF 2004. Functional and phylogenetic analyses of a melanocortin- 4 receptor mutation in domestic pig. Livestock Production Science 26, 75-86.

Koohmaraie M, Kent MP, Shackelford SD, Veiseth E and Wheeler TL 2002Meat tenderness and muscle growth: is there any relationship? Meat Science 62, 345-352.

Leach LM, Ellis M, Sutton DS, McKeith FK and Wilson ER 1996. The growth performance, carcass characteristics, and meat quality of halothane carrier and negative pigs. Journal of Animal Science 74, 934-943.

Lebret $B$, Juin $H$, Noblet J and Bonneau M 2001. The effects of two methods of increasing age at slaughter on carcass and muscle traits and meat sensory quality in pigs. Animal Science 72, 87-94.

Meulemans A, Dotreppe O, Leroy B, Lecocq H, Istasse L and Clinquart A 2002. Prediction of technological and organoleptic properties of porcine meat by near infrared spectroscopy. Proceedings of the 48th International Congress of Meat Science and Technology, Rome, Italy, pp. 822-823.

Oksbjerg N, Petersen JS, Sørensen IL, Henckel P, Vestergaard M, Ertbjerg P, Moller AJ, Bejerholm C and Stoier S 2000. Long-term changes in performance and meat quality of Danish Landrace pigs: a study on a current compared with an improved genotype. Animal Science 71, 81-92.

Otto G, Roehe R, Looft H, Thoelking L, Knap PW, Rothschild MF, Plastow GS and Kalm E 2007. Associations of DNA markers with meat quality traits in pigs with emphasis on drip loss. Meat Science 75, 185-195.

Óvilo C, Fernández A, Rodríguez MC, Nieto M and Silió L 2006. Association of $M C 4 R$ gene variants with growth, fatness, carcass composition and meat and fat quality traits in heavy pigs. Meat Science 73, 42-47.

Park HB, Carlborg Ö, Marklund L and Andersson L 2002. Melanocortin-4 receptor (MC4R) genotypes have no major effect on fatness in a Large White $\times$ Wild Boar intercross. Animal Genetics 33, 155-157.

Sellier P 1998. Genetics of meat and carcass traits. In The genetics of the pig (ed. MF Rothschild and A Ruvinsky), pp. 463-510. CAB International, New York, USA.

Stachowiak M, Szydlowski M, Obarzanek-Fojt M and Switonski M 2005. An effect of a missense mutation in the porcine melanocortin-4 receptor (MC4R) gene on production traits in Polish pig breeds is doubtful. Animal Genetics 37, 55-57.

Statistical Packages for the Social Sciences 2003. SPSS 12.0 for windows. SPSS Inc., Chicago, IL, USA.

Van den Maagdenberg K, Stinckens A, Claeys E, Buys N and De Smet S 2005. Preliminary study of the effect of the IGF-II genotype on meat quality in pigs. Proceedings of the 56th Annual Meeting of the EAAP, Uppsala, Sweden, p. 219.

Van Laere A, Nguyen M, Braunschweig M, Nezer C, Collette C, Moreau L, Archibald AL, Haley C, Buys N, Tally M, Andersson G, Georges $M$ and Andersson $L$ 2003. A regulatory mutation in IGF2 causes a major QTL effect on muscle growth in the pig. Nature $425,832-836$ 